\title{
Physicists want 1996 link-up with LHC
}

\begin{abstract}
Washington. High-energy physicists in the United States are working on a new strategy for their field which could lay the groundwork for a substantial US involvement from 1996 in the Large Hadron Collider (LHC) being planned by the European Laboratory for Particle Physics (CERN) in Geneva.

"It is perfectly possible for us to provide an intellectual contribution [to the LHC] now, with the expectation of money to follow later," says George Trilling of the Lawrence Berkeley Laboratory in California, one of the many physicists having to come to terms with the recent death of the Superconducting Super Collider (SSC, see Nature 365, 773; 1993),
\end{abstract}

At present, the several hundred US scientists who work at CERN on salaries paid by US organizations do not have to pay for access to its experimental facilities. This arrangement has been based on expectations that a reciprocal arrangement would have given Europeans access to the SSC.

With the demise of the SSC, a new arrangement is being sought. The 19 European governments who make up CERN would like that arrangement to extend to US participation in the construction and operation of the LHC.

One likely area for US involvement is in the design and construction of the LHC's huge detectors. Gil Gilchriese of Lawrence

\section{CERN views a suitor with caution}

Geneva. As the United States prepares plans to salvage what it can from the wreckage of the Superconducting Super Collider (SSC), the European Laboratory for Particle Physics (CERN) in Geneva is considering how its own equivalent project might benefit.

Christopher Llewellyn-Smith, who takes over from Carlo Rubbia as CERN's director-general next month, says it is too soon to start making specific plans for bringing US particle physicists on board the proposed Large Hadron Collider (LHC). Formal discussion are unlikely to start for at least six months.

But talks are already taking place between European and US scientists on areas of potential collaboration. When the dust eventually settles, the most likely outcome is that the United States will be brought into the LHC programme through some form of special cooperative agreement.

One problem hampering negotiations is that the LHC is not likely to receive approval from CERN's 19 member states until next summer at the earliest, and possibly even later. Another is that the US Department of Energy's High Energy Physics Advisory Panel, which is currently drawing up plans for post-SSC particle physics in the United States, is not due to report until May (see above).

The CERN council meets in Geneva this week (16 December) to discuss the final LHC budget proposals, which have already been cut back in response to criticism from member states. Germany in particular has expressed concern that the cost of the LHC, which now stands just above SFr2 billion (US\$1.34 billion), has increased around 10 per cent in real terms from initial estimates in 1989.

Llewellyn-Smith, backed by most member states, wants the proposed modified budget to be approved independently of any potential agreement with the United States, even though such an agreement could bring in extra money. At the same time, he is keen to find ways of making use of the scientific and technological expertise already built up on the SSC project. "Specific collaborations negotiated independently with the Americans could allow us to expand on the experiments we can plan," he says.

Luciano Maiani, director of Italy's National Institute of Nuclear Physics and the country's delegate to the CERN council, agrees. The LHC should be open to international collaboration in every possible way, he says. "But we can't afford to make approval of the $\mathrm{LHC}$ conditional on obtaining outside money."

One possible arrangement is for the United States to become an 'associate member'. But this would require a rule change, because such a category does not yet exist.

Another option is for the United States to becomes a full member of CERN. But this is unlikely to be acceptable to current member states. One reason is that the annual membership fee, which is based loosely on a country's gross national product and would reach the limit of 25 per cent of its budget allowed by CERN as a contribution from a single country; this might be more than the United States would be willing to pay.

And even if it did feel able to afford this sum, there is likely to be further opposition. As a full member, the United States' budget contribution would be the largest of any member state, an uncomfortable prospect in the eyes of some countries, such as Italy, that wish to preserve CERN's status as a European organization.

Alison Abbott
Berkeley says he does not think the United States will build its own detector. Instead, he thinks it is likely to make "a significant investment, of up to 20 per cent" in the two existing European detector collaborations from 1996. (That is the earliest date at which the cumbersome US budget process can be expected to yield new money for any international collaboration.)

In the meantime, US high-energy physicists are fighting to save some of the knowledge and expertise built up at the SSC Laboratory in Texas.

Scientists involved in the detector work want \$15-\$20 million in the current financial year to complete their research. But John Peoples, director of Fermilab and now also director of the SSC, says support at that level is "out of the question".

"Congress doesn't see it as part of the orderly termination" of the SSC, says Peoples. Some support may be forthcoming, he says, but only if Congress is convinced that progress is being made in saving money elsewhere as the project is shut down.

Hazel O'Leary, the US Secretary of Energy, last month asked her High Energy Physics Advisory Panel (HEPAP), whose main advice up to then had been "build the SSC", to set up a subpanel to report next May on a future strategy. O'Leary, in turn, is due to report to Congress in July.

After a preliminary discussion, Stan Wojcicki, the head of HEPAP, has told O'Leary that three issues need immediate attention. The first is that some of the $\$ 640$ million allocated in the current financial year for the orderly closure of the SSC should go to support detector research and development, so that research already completed can be documented properly.

Second, HEPAP would like between $\$ 20$ and $\$ 30$ million of the budget for fiscal year 1995 (which begins next October), now under discussion by the administration, for detector research. This would put US physicists in a good position to participate in the $\mathrm{LHC}$ at a later date. And the panel also wants an end to the recent decline in the non-SSC high-energy physics budget.

Once these issues have been addressed, HEPAP says it will look at the prospects for longer term involvement with the LHC. O'Leary has told the panel that she wants it to focus on the options for creating "a truly international framework" for future work in high-energy physics.

In an effort to involve more physicists in the discussion, the particle and fields division of the American Physical Society is planning its own effort to redefine priorities. Subpanels will be set up, says Roberto Peccei, the head of the division, to produce a preliminary assessment for HEPAP in May, and a final report the following January. 